\title{
Assessing the Utility of Sentinel-1 C Band Synthetic Aperture Radar Imagery for Land Use Land Cover Classification in a Tropical Coastal Systems When Compared with Landsat 8
}

\author{
Mary Lum Fonteh ${ }^{1 *}$, Fonkou Theophile ${ }^{2}$, M. Lambi Cornelius' ${ }^{3}$, Russell Main ${ }^{4}$, \\ Abel Ramoelo ${ }^{4,5}$, Moses Azong Cho ${ }^{4,5}$ \\ ${ }^{1}$ Department of Geography, Higher Teacher's Training College, University of Bamenda-Bambili, \\ Bamenda, Cameroon \\ ${ }^{2}$ Department of Plant Biology, Faculty of Science, University of Dschang, Dschang, Cameroon \\ ${ }^{3}$ Department of Geography, Faculty of Social and Management Sciences, University of Buea, Buea, Cameroon \\ ${ }^{4}$ Natural Resource and the Environment, Earth Observation Unit, Council for Scientific and Industrial Research \\ (CSIR), Pretoria, South Africa \\ ${ }^{5}$ School of Agriculture, Earth and Environmental Sciences, University of KwaZulu-Natal, \\ KwaZulu-Natal, South Africa \\ Email: "mariefontehniba3@gmail.com
}

Received 20 June 2016; accepted 7 August 2016; published 10 August 2016

Copyright (C) 2016 by authors and Scientific Research Publishing Inc.

This work is licensed under the Creative Commons Attribution International License (CC BY). http://creativecommons.org/licenses/by/4.0/

(c) (i) Open Access

\section{Abstract}

Cloud cover constitutes a major obstacle to land cover classification in the humid tropical regions when using optical remote sensing such as Landsat imagery. The advent of freely available Sentinel-1 C band synthetic aperture radar (SAR) imagery offers new opportunities for land cover classification in frequently cloud covered environments. In this study, we investigated the utility of Sentinel-1 for extracting land use land cover (LULC) information in the coastal low lying strip of Douala, Cameroon when compared with Landsat enhanced thematic mapper (TM). We also assessed the potential of integrating Sentinel-1 and Landsat. The major LULC classes in the region included water, settlement, bare ground, dark mangroves, green mangroves, swampy vegetation, rubber, coastal forest and other vegetation and palms. Textural variables including mean, correlation, contrast and entropy were derived from the Sentinel-1 $\mathrm{C}$ band. Various conventional image processing techniques and the support vector machine (SVM) algorithm were applied. Only four

\footnotetext{
${ }^{*}$ Corresponding author.
}

How to cite this paper: Fonteh, M.L., Theophile, F., Cornelius, M.L., Main, R., Ramoelo, A. and Cho, M.A. (2016) Assessing the Utility of Sentinel-1 C Band Synthetic Aperture Radar Imagery for Land Use Land Cover Classification in a Tropical Coastal Systems When Compared with Landsat 8. Journal of Geographic Information System, 8, 495-505. 
land cover classes (settlement, water, mangroves and other vegetation and rubber) could be calibrated and validated using SAR imagery due to speckles. The Sentinel-1 only classification yielded a lower overall classification accuracy $(67.65 \%$ when compared to all Landsat bands $(88.7 \%))$. The integrated Sentinel-1 and Landsat data showed no significant differences in overall accuracy assessment $(88.71 \%$ and $88.59 \%$, respectively). The three best spectral bands $(5,6,7)$ of Landsat imagery yielded the highest overall accuracy assessment $(91.96 \%)$. in the study. These results demonstrate a lower potential of Sentinel-1 for land cover classification in the Douala estuary when compared with cloud free Landsat images. However, comparable results were obtained when only broad classes were considered.

\section{Keywords}

\section{SAR, Landuse/Land Cover, Classification, Landsat Enhanced Thematic Mapper}

\section{Introduction}

Information on land use land cover (LULC) is a vital element in forming policies regarding economic, demographic, and environmental issues at national, regional and global scales. The Douala coastal low lying urban region, like other urban areas in the world, is undergoing rapid changes in LULC. The region is losing its mangrove forest because of conversion to urban settlement and industrial developments. Mapping LULC of this coastal strip in a timely and accurate manner is thus of immense importance for urban planning, land use planning, conservation of biodiversity and sustainable management of land resources.

Reference [1] highlighted the fact that remotely sensed imageries provide an efficient means of obtaining information on temporal trends and spatial distribution of urban areas needed for understanding, modelling and projecting LULC changes. Improvements in satellite image processing and Geographic Information System (GIS), implies that change detection can be easily and rapidly conducted as in [2] [3].

Land cover and other biophysical data are crucial in environmental assessments studies as in [4]-[6]. They offer basic data on spatially explicit patterns of landscape features and associated processes that affect fluxes of biota, water, energy, and materials. When these data are related spatially and temporally they can provide the basic elements for modelling fundamental environmental processes at a range of scales. Results of spatially explicit landscape change when intersected with distributions of sensitive resources and associated processes, enables an assessment of possible risk. For example, land cover and other biophysical and human demographic data have been used to evaluate vulnerability and risks related to natural and anthropogenic hazards such as sea level rise in Turkey as in [7] and flooding as in [8].

Space-borne multispectral sensors such as Landsat are widely used to map LULC change as in [9] [10]. However, the use of Landsat is limited in tropical regions because of frequent cloud cover. Landsat is a passive sensor which detects energy that is reflected by the object (e.g. vegetation) from the sun (a natural source) and is affected by clouds and therefore can only be used during daylight. On the other hand, active sensors such as Radio Detection and Ranging (RADAR) provide their own source of illumination (microwave energy) and measure the backscattered energy. They therefore have the advantage of operating at longer wavelengths not impeded by cloud cover or a lack of illumination and can acquire data over a site during day or night time under all weather conditions as in [11]-[13]. However, the use of RADAR for LULC mapping in the tropics is still not widespread because of the lack of freely available images as is the case with passive sensors. The advent of Sentinel-1, that performs C-band Synthetic Aperture RADAR (SAR), could increase the use of RADAR remote sensing for LULC mapping in tropical regions which are frequently covered by clouds. Its utility for mapping various land cover types including vegetation types, water bodies and various kinds of built-up areas is yet not fully established.

Therefore, the aim of the study was to investigate the utility of Sentinel-1 for extracting land use land cover (LULC) information in the coastal low lying region of Douala, Cameroon when compared to Landsat enhanced thematic mapper (TM), and whether an integrated Sentinel-1/Landsat provide an improved classification of LULC types. 


\section{Methodology of Land Use Land Cover Classification}

\subsection{Study Area}

This study is limited to the coastal low lying region of Douala, Cameroon (Figure 1) between latitude 3.794 to $4.050 \mathrm{~N}$ and longitude 9.458 to $9.822 \mathrm{E}$. The region consists of varied wetlands, mangroves, coastal plains, creeks and sandy beaches as the main geomorphological attributes.

\subsection{Image Acquisition and Pre-Processing}

Cloud free Landsat 8 images were downloaded from the web pages of Global Visualisation Viewer (www.glovis.usgs.gov) and EarthExplorer (www.earthexplorer.usgs.gov).

The area of interest was obtained by sub setting the original image using the region-of-interest (ROI) in ENVI (Environment for Visualisation Images) 4.8. This was necessary to limit the processing time of different images, as large scenes will take long to be processed. Atmospheric correction was done using the AtCOR 2/3 software. The conditions specified for the study area image in AtCOR was the "tropical urban" conditions due to the nature of the study area.

The different spectral bands of the image were assigned appropriate band names and wavelengths and stacked together. Training and validation data for the classification were obtained from high resolution Google earth map. These were imported to ArcGIS 10.3. With the help of Arc toolbox, in the GIS environment, the KMZ data were converted to shape files and exported to ENVI (Environment for Visualisation Images) 4.8 software where they were converted to ENVI vector files. The vector layers were overlaid on the image of the study area to establish the training and validation polygons using the ROI tool.

\subsection{SAR Image Processing}

SAR, C-band Sentinel-1 data were downloaded from the European space agency (ESA) website https://scihub.esa.int/dhus/. The Sentinel-1 toolbox from ESA was used for processing the images. Images were subsetted to obtain the desired area of interest. Image calibration was applied to SAR imagery using the Sentinel-1

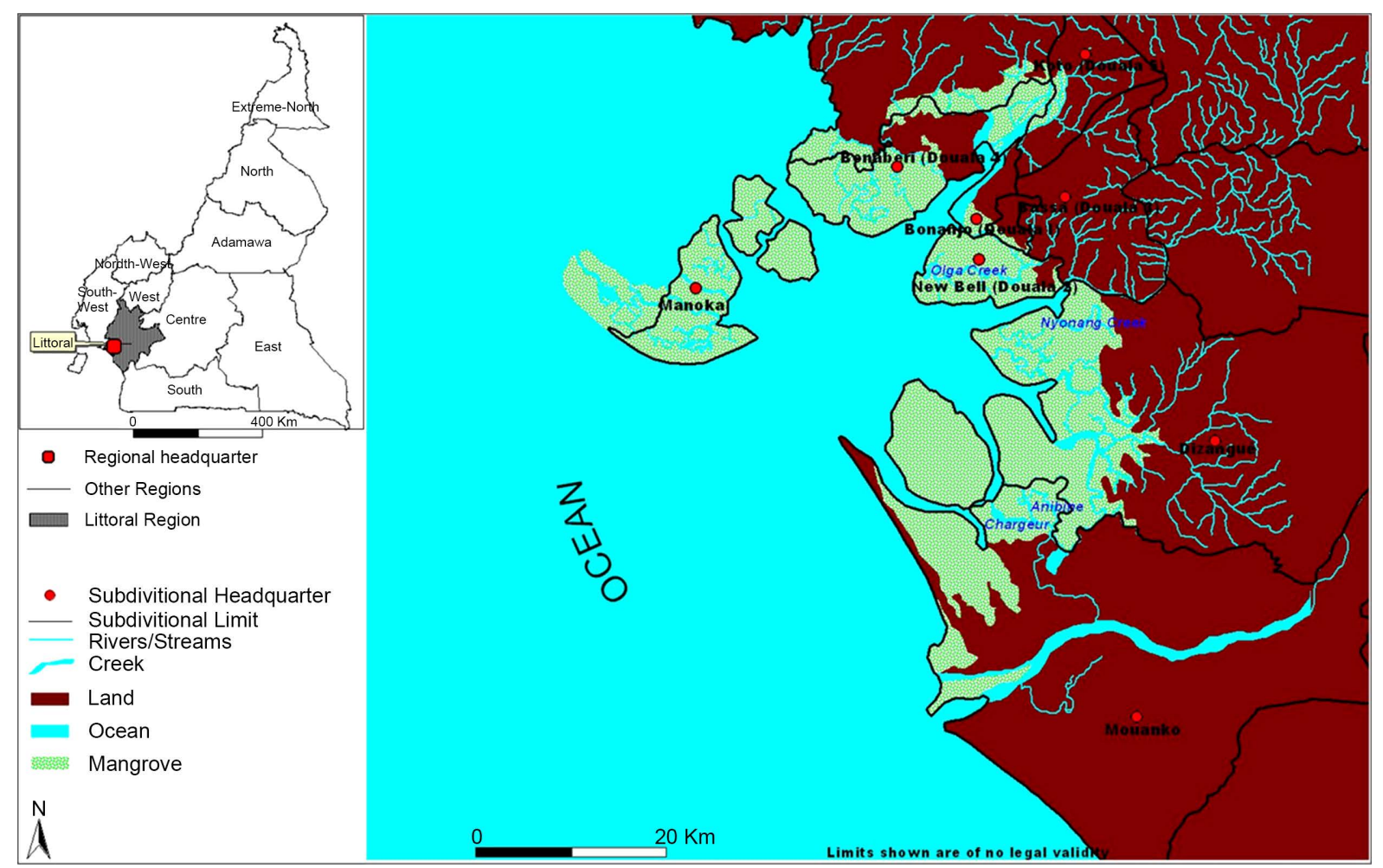

Figure 1. Study area adapted from Google Earth, 2010. 
toolbox kit. Calibration was done to radiometrically correct the SAR image so that the pixel values truly represent the radar backscatter of the reflecting surface. SAR images are subjected to an inherent granular noise called speckle which usually degrades the quality of the image and makes interpretation and classification difficult. Images were speckled filtered using the Gamma filter in the SNAP tool box kit so as to smoothen the noise in the SAR image.

\subsection{Selection of Textural Measures for SAR Image}

Reference [14]-[16] indicates that unprocessed SAR images cannot be used as they are because of inherent speckle noise resulting from constructive and deconstructive interference of reflected signals. Consequently, in the classification of SAR images in the ENVI software additional signal processing procedures were employed such as speckle filtering and texture extraction, which could help in the interpretation of radar images. Studies have shown that texture is the most important source of information in high resolution radar images as in [10] [17]. The Grey Level Co-occurrence Matrix (GLCM) based textural measures have extensively been used to enhance land cover mapping and have been found out that they outperformed other texture methods as in [18]. This is because the presence of speckle noise can result in a high degree of misclassification as in [9] [19] [20].

Different texture combination was explored for this study and it was realised that contrast, mean, correlation and entropy with a window size of $9 \times 9$ and $11 \times 11$ brought out settlement nicely as a class; vegetation was all classified as mangroves. Larger windows lead to more stable texture features but turn to blur the edges, while smaller window sizes lead to erroneous boundary delineation and misclassify the boundary itself as a class as has similarly been reported by several authors as in [16]-[18] [21]. Different windows were explored and the best window was the $9 \times 9$ window.

Reference [22] indicated that different filters have been used to de-noise, sharpen and smoothen images as it improves on the extraction of vital information for image processing. For example, 10\% improved classification accuracy was obtained for a study site in Dadaad, Kenya when variance texture was applied. Unfortunately, no combination of filters and textures has been nicely ascertained to improve the extraction of information from images before processing as in [9]. Consequently, different combinations of filters were assessed and the combination of gamma, kuan and enhanced lee filter in that order were observed to bring out water, mangroves and rubber and other vegetation as a class with a filter size of $3 \times 3$ windows.

Settlement as a class was poorly represented from the classification using the three combined filters. Consequently, the GLCM texture of mean, correlation, contrast and entropy of size 9 windows were stacked with size 3 of gamma, kuan and enhanced Lee filters.

\subsection{Integration of SAR and Landsat 8 ETM Images}

The Sentinel-1 C band images and Landsat imagery were orthorectified to the same Universal Transverse Mercator (UTM) map projection. They were merged together into a common image format, with SAR imagery inserted as extra bands. This was done by resampling the SAR image to a $30 \mathrm{~m}$ pixel size using the nearest neighbour method and co-registered pixel by pixel with $30 \mathrm{~m}$ pixel size Landsat imagery. This step prepares the integrated multi-sensor data for classification. Integration is done to investigate its efficiency in improving LULC mapping in an urban area.

\subsection{Land Cover Classification}

Different software's are used for image classification. This study made use of ENVI 4.8. The classification was conducted using the workflow represented in Figure 2.

Support vector machine (SVM), a supervised classifier algorithm which is a non-parametric algorithm was used for classification.

It is robust and useful for high dimensional data and they distinguish classes based on a decision function as in [23]-[25]. This function is as a result of used number of dimension (planes or lines). It results from the maximum separability of classes under investigation called hyper plane where pixels defining such hyper planes are called support vectors. Other studies have highlighted the robustness of SVM algorithm over other classifiers in LULC classification as in [26]-[29]. Reference [26] demonstrated that SVM had a higher overall accuracy than maximum likelihood classifier in land use mapping in Karaj, Iran. 


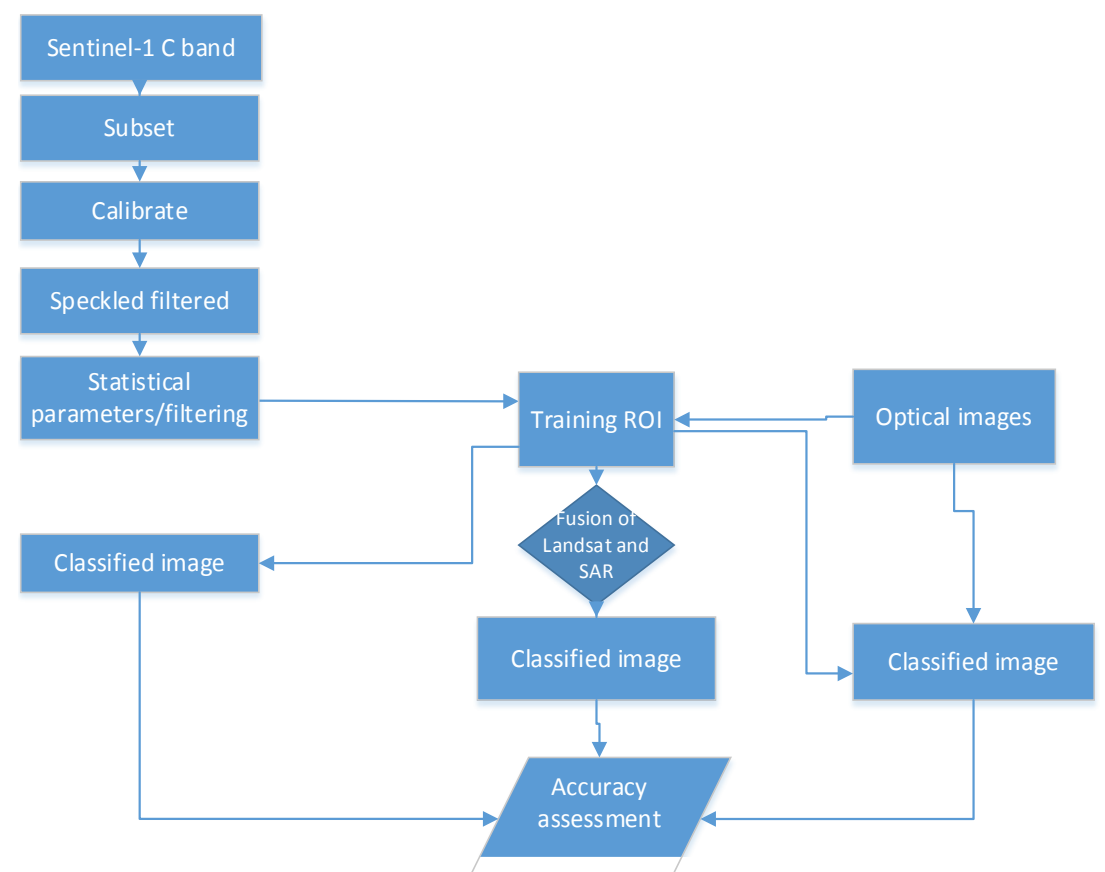

Figure 2. Flow chart of optical and Sentinel-1 C band image classification.

\subsection{Classification Accuracy Assessment}

The n-D visualizer is useful for checking the separability of land classes when ROIs are used as input into supervised classifications. For good classification results using these ROIs, the groups of pixels for the different ROIs should be separate from each other and should not overlap.

Additionally, the Jeffries-Matusita and Transformed Divergence separability measures were used for computing ROIs separability. These values range from 0 to 2.0 and indicate how well the selected ROI pairs are statistically separate. Values greater than 1.9 indicate that the ROI pairs have good separability.

Finally, to assess the overall quality of the images, post classification assessment was done using the confusion matrix. References [30] [31], defines accuracy estimation as the quantification of mapping with the aid of remote sensing data to group classification conditions. This is vital in the evaluation of classification algorithms and also the determination of error levels that might be contributed by the image. The classification is expressed in the form of an error matrix also known as confusion matrix as in [26]. Many methods have been discussed for accuracy assessment in remote sensing; in this paper the overall accuracy assessment was tested.

\section{Results and Discussion}

\subsection{Descriptive Analysis of the Land Use Land Cover Classes}

The goal was to produce LULC map of Douala-Cameroon; consequently, LULC maps were produced for 1) Landsat 8 only; 2) integrated Landsat and SAR; 3) SAR only imagery (Figure 3, Figure 4 and Figure 5) for the Douala low lying coastal area. On one hand, nine land cover types or classes could be distinguished using Landsat 8 and the integrated Landsat and SAR classification, namely: water, settlement, bare ground, dark mangroves, green mangroves, swampy vegetation, forest vegetation/others, and palms.

On the other hand, only four classes could be accurately classified using the SAR imagery (Figure 5). The use of texture (mean, contrast, entropy, correlation) on the SAR image brought out settlement as a class, and all vegetation was classified as mangroves with blocky image. Water as a class could not be distinguished. The use of size 3 filters (gamma, kuan and enhanced lee) on the other hand failed to bring out settlement as a class but brought out rubber plantation, water and mangroves and other vegetation clearly. Consequently, merging filtered SAR bands and textured SAR bands highlighted four trained important classes (water, settlement, rubber and mangroves and other vegetation). Probably because the backscatter from rubber fields was distinct and enabled this class to be classified accurately. 


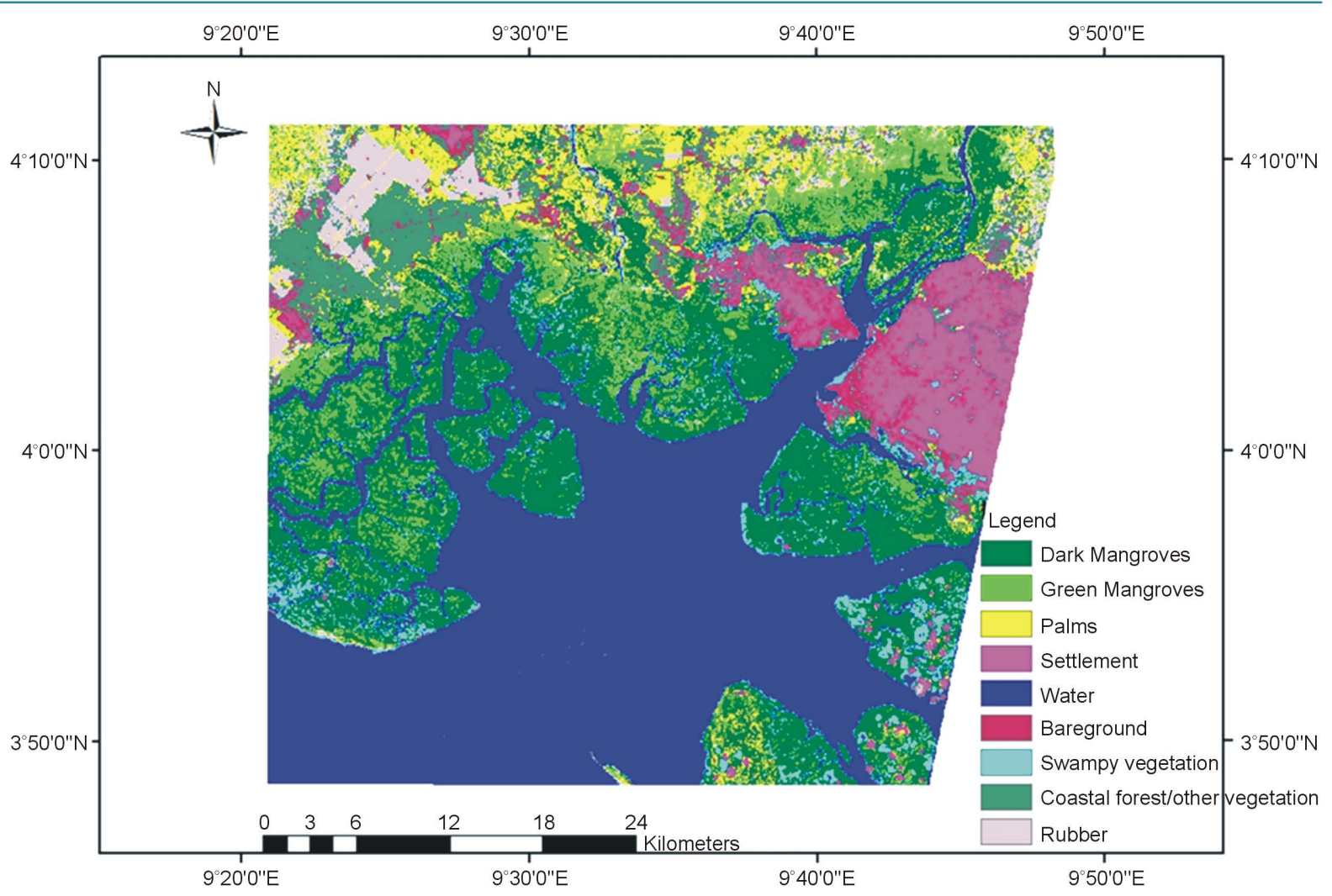

Figure 3. Classified image of Landsat 8 only of the Douala-Tiko coastal strip.

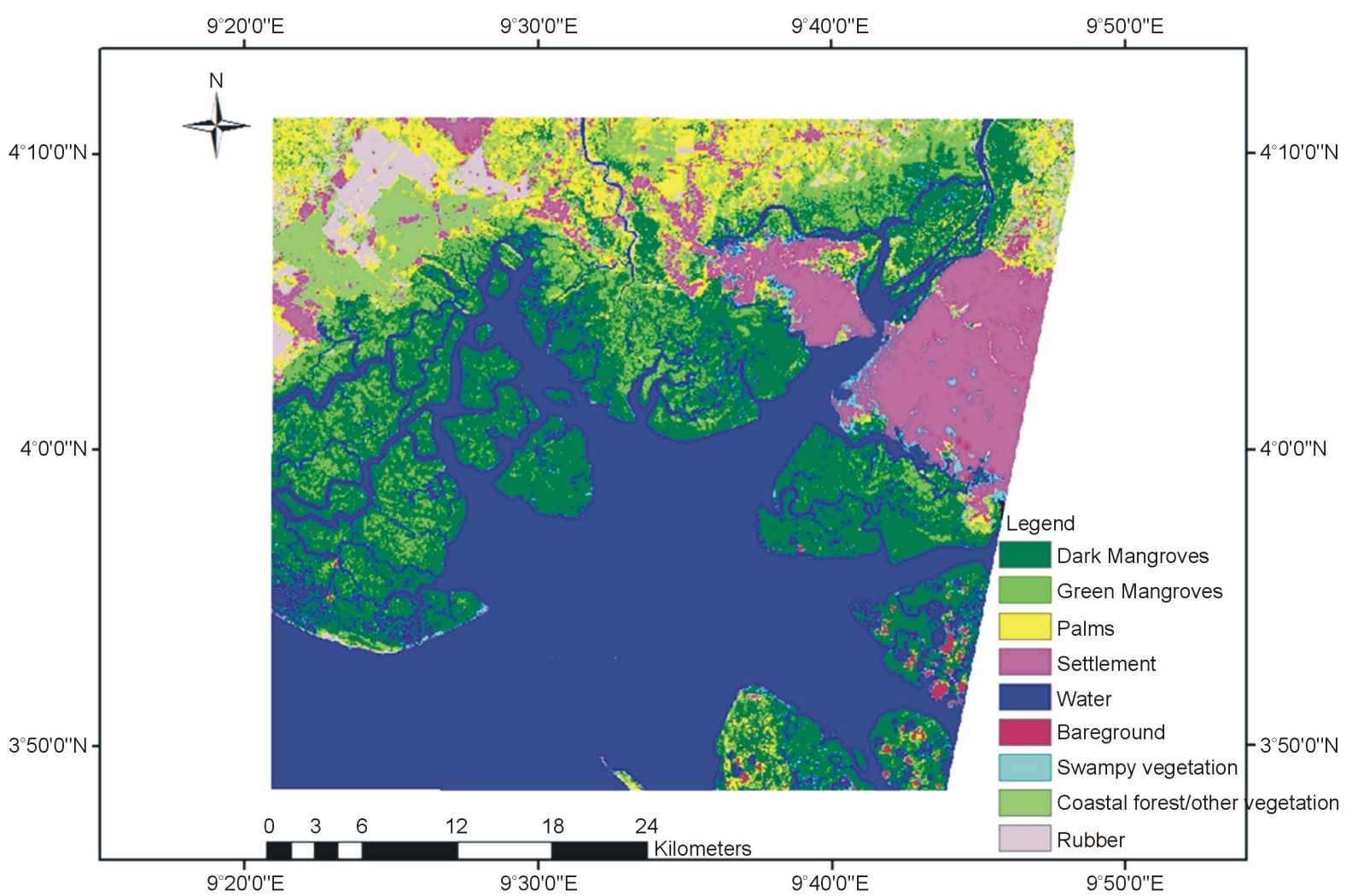

Figure 4. Integrated classified optical and radar imagery of the Douala-Tiko coastal strip. 


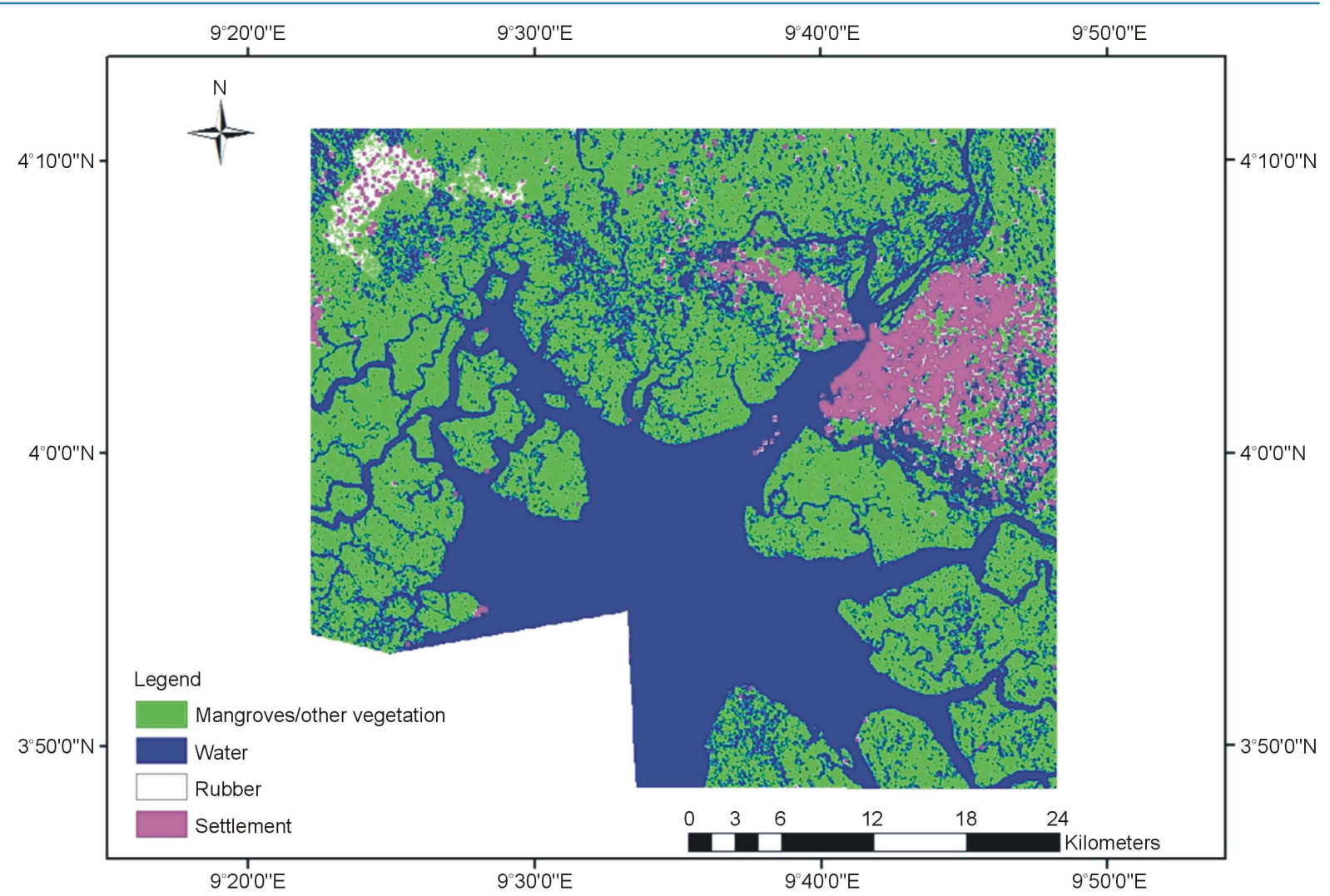

Figure 5. Classified image of Douala using SAR only image.

\subsection{Accuracy Assessment Using Confusion Matrix}

From Figure 6, the n-D visualizer and the separability report showed a high discrimination potential for the integrated spectral and SAR, all Landsat spectral bands and three Landsat best bands (5, 6, 7). The n-D visualizer and its separability report for SAR image classification was however not good but acceptable for further analysis.

The resulting integrated Landsat and SAR, all Landsat spectral bands, three best bands of Landsat and SAR only image yielded overall map accuracies for all nine classes of 88.59\%, 88.71\%, 91.96\% and 67.65\% respectively (Table 1).

The overall accuracy assessment was 3.7\% improved with three best bands of Landsat data when compared with the integrated Landsat and SAR imagery. Image integration of Landsat and SAR does not improve the results of the overall accuracy assessment of classification as compared to all Landsat spectral bands. Reference [32] also indicated no improvement of overall classification of integrated SAR and Landsat imagery. Green mangroves were classified with a lower producer's accuracy (54.55\%) than other classes. This is due to the combination of omission and commission errors particularly mixing with swampy vegetation and mixing with coastal forest areas.

Reference [33] in his three test sites in Europe with ERS SAR in a mapping project, adopted a classification of four classes (urban areas, water, forest and sparse vegetation). Reference [34] used only two classes (urban and non-urban) using ERS SAR interferometric images of South Wales, United Kingdom. This is probably due to the inherent granular noise found in SAR images and the uncertainty of SAR image backscattering information. However, thematic maps of this nature could be very valuable in other fields of application.

Remotely sensed data captured in digital forms can easily be combined with other types of ground features information through GIS techniques. The obtained LULC map of Douala can be applied for mapping water resources and used for identifying potential water resources that could be polluted. Land use pattern and land cover indicates the pressure on ground water use. Throughout the world, agricultural activities followed by industry and domestic use are the important land use type that requires massive water resources. Cameroon is not 


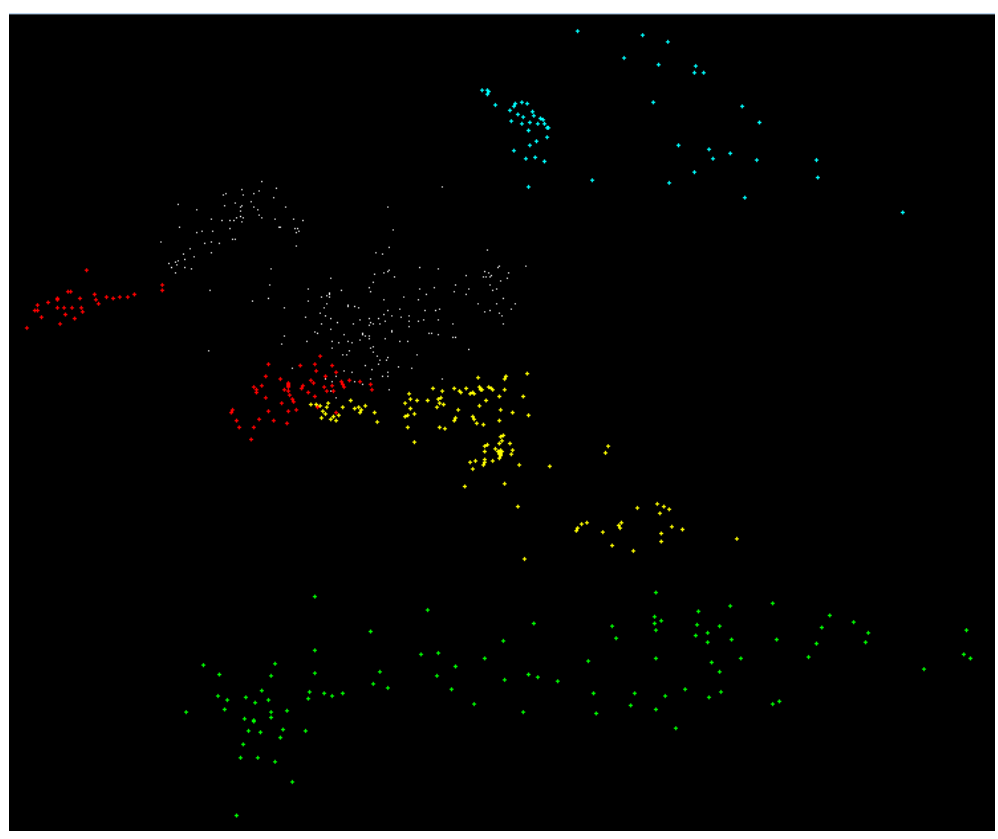

Figure 6. Clustering of training sites in $\mathrm{n}-\mathrm{D}$ visualisation indicating separability of different LULC classes.

Table 1. Accuracy assessment of LULC classification of used imagery.

\begin{tabular}{|c|c|c|c|c|c|c|c|c|}
\hline & \multicolumn{2}{|c|}{ Spectral and SAR } & \multicolumn{2}{|c|}{ Spectral (All bands) } & \multicolumn{2}{|c|}{$\begin{array}{c}\text { Spectral } \\
\text { (best bands: 5, 6, 7) }\end{array}$} & \multicolumn{2}{|c|}{ SAR only } \\
\hline & $\begin{array}{c}\text { Producer's } \\
\text { Accuracy } \\
\text { (\%) }\end{array}$ & $\begin{array}{l}\text { User's } \\
\text { Accuracy } \\
\text { (\%) }\end{array}$ & $\begin{array}{c}\text { Producer's } \\
\text { Accuracy } \\
\text { (\%) }\end{array}$ & $\begin{array}{l}\text { User's } \\
\text { Accuracy } \\
\text { (\%) }\end{array}$ & $\begin{array}{c}\text { Producer's } \\
\text { Accuracy } \\
\text { (\%) }\end{array}$ & $\begin{array}{c}\text { User's } \\
\text { Accuracy } \\
\text { (\%) }\end{array}$ & $\begin{array}{c}\text { Producer's } \\
\text { Accuracy } \\
(\%)\end{array}$ & $\begin{array}{c}\text { User's } \\
\text { Accuracy } \\
\text { (\%) }\end{array}$ \\
\hline Water & 100 & 89.47 & 100 & 94.44 & 100 & 94.44 & 100 & 66.67 \\
\hline Bare ground & 88.89 & 88.89 & 85.71 & 80 & 81.82 & 81.82 & & \\
\hline Settlement & 100 & 93.75 & 100 & 93.75 & 92.31 & 85.71 & 66.67 & 88.89 \\
\hline Palms & 83.33 & 90.91 & 80 & 100 & 80 & 88.89 & & \\
\hline Vegetation forest/others & 88.89 & 72.73 & 75 & 80 & 84.62 & 84.62 & & \\
\hline Dark mangroves & 100 & 61.54 & 100 & 72.73 & 100 & 100 & & \\
\hline Green mangroves & 54.55 & 100 & 72.73 & 100 & 88.89 & 100 & 77.78 & 58.33 \\
\hline Swampy vegetation & 71.43 & 100 & 78.57 & 100 & 91.67 & 100 & & \\
\hline Rubber & 100 & 100 & 100 & 86.36 & 100 & 95 & 57.14 & 66.67 \\
\hline Overall accuracy & \multicolumn{2}{|c|}{88.5965} & \multicolumn{2}{|c|}{88.7097} & \multicolumn{2}{|c|}{91.9643} & \multicolumn{2}{|c|}{67.647} \\
\hline
\end{tabular}

an exception as the percentages water usages stands at $73.8 \%, 18.2 \%$ and $8 \%$ for agricultural, domestic usages and industrial activities respectively as to total withdrawal as in [35]. And so, if a coastal area is mainly used for agriculture and industrial activity as the case of the study area, then the area will be vulnerable to impacts of SLR due to overexploitation of water resources which are the driving forces for the sediment budget and salt water intrusion.

\section{Conclusions}

The results obtained by employment of GIS and RS applications have highlighted the different LULC types 
(water, settlement, swampy vegetation, palms, bare-ground, dark mangroves, green mangroves, rubber, coastal forest and other vegetation) of the study area using all Landsat spectral bands, three best Landsat bands, integrated Landsat and SAR images. Four classes (rubber, water, settlement and mangroves and other vegetation) were obtained from the classification of SAR imagery only.

The results of classification using all Landsat spectral bands, three best bands $(5,6,7)$ of Landsat, integration of Landsat and SAR, and SAR imagery with the SVM classifier gave an overall accuracy assessment of $88.71 \%$, 91.96\%, 88.59\% and 67.65\% respectively. The best method of LULC classification was obtained when three best bands $(5,6,7)$ of Landsat imagery was used. The overall accuracy assessment of LULC was improved by 3.7\% when three best bands of Landsat imagery was used when compared to the integrated Landsat and SAR imagery's accuracy assessment. This indicates that the integration of SAR and Landsat imagery do not improve the accuracy result tremendously when compared to the use of Landsat imagery alone. The results further demonstrated that for identifying LULC classes, Sentinel-1 C band imagery yielded poor results using the SVM algorithm.

Land use pattern is one of the main human influenced parameters that have been indicated to promote salt water intrusion into ground water resources, rivers and estuaries as a result of sea level rise as in [7] [36] [37]. Furthermore, urbanisation influences the vulnerability of coastal areas and increases human pressure on natural systems. Hence, coastal areas used for agricultural purposes, settlements or wetlands are an integral aspect of risk assessment of SLR hazards on fresh water resources. This study illustrates the use of RS and GIS as important technologies for extracting LULC which can be very challenging with the use of conventional mapping techniques. Risk assessment of environmental hazards is made possible by these technologies in less time, at low cost and with better accuracy.

\section{Acknowledgements}

This paper was realised through a three months internship accorded to Mary Lum Fonteh Niba by the Council for Scientific and Industrial research (CSIR), Pretoria in developing her skills in remote sensing and GIS modelling as part of her Ph.D. thesis.

\section{References}

[1] Elvidge, C.D., Sutton, P.C. and Wagner, T.W. (2004) Urbanization. In: Gutman, G., Janetos, A., Justice, C., et al., Eds., Land Change Science: Observing, Monitoring, and Understanding Trajectories of Change on the Earth's Surface, Kluwer Academic Publishers, Dordrecht, 315-328.

[2] Jensen, J.R. (2004) Introductory Digital Image Processing: A Remote Sensing Perspective. 3rd Edition, Prentice-Hall, Inc., New York, 316.

[3] Macleod, R.D. and Congalton, R.G. (1998) A Quantitative Comparison of Change Detection Algorithms for Monitoring Eelgrass from Remotely Sensed Data. Photogrammetric Engineering and Remote sensing, 6, 207-216.

[4] Wickham, J.D., Jones, K.B., Riitters, K.H., O’Neill, R.V., Tankersley, R.D., Neale, A.C., Smith, E.R. and Chaloud, D.J. (1999) Characterizing Cumulative Environmental Impacts on Mid-Atlantic Watersheds. Environmental Management, 9, 553-560. http://dx.doi.org/10.1007/s002679900254

[5] Bradley, M.P. and Smith, E.R. (2004) Using Science to Assess Environmental Vulnerabilities. Environmental Monitoring and Assessment, 94, 1-7. http://dx.doi.org/10.1023/B:EMAS.0000016875.89092.e7

[6] Theobald, D.M. and Romme, W.H. (2007) Expansion of the US Wild Land-Urban Interface. Landscape and Urban Planning, in press. http://dx.doi.org/10.1016/j.landurbplan.2007.06.002

[7] Ozyurt, G. and Ergin, A. (2009) Application of Sea Level Rise Vulnerability Assessment Model to Selected Coastal Regions of Turkey. SI 56. Proceedings of the 10th International Coastal Symposium, 56, 248-251.

[8] Sanders, R.F., Shaw, H., MacKay, H., Galy and Foote, M. (2006) National Flood Modelling for Insurance Purposes: Using IFSAR for Flood Risk Estimation in Europe. Hydrology and Earth System Sciences, 9, 449-456. http://dx.doi.org/10.5194/hess-9-449-2005

[9] Huang, H., Legarsky, J. and Othman, M. (2007) Land-Cover Classification using Radarsat and Landsat Imagery for St. Louis, Missouri. Photogrammetric Engineering and Remote Sensing, 73, 37-43. http://dx.doi.org/10.14358/PERS.73.1.37

[10] Ulaby, F.T., Moore, R.K. and Fung, A.K. (1982) Microwave Remote Sensing Active and Passive from Theory to Applications. Vol. III, Artech House, Massachusetts, 1115-1120. 
[11] Henderson, F.M. and Xia, Z.G. (1997) SAR Applications in Human Settlement Detection, Population Estimation and Urban Land Use Pattern Analysis: A Status Report. IEEE Transactions on Geoscience and Remote Sensing, 35, 79-85. http://dx.doi.org/10.1109/36.551936

[12] Dell'Aqua, F. and Gamba, P. (2003) Texture-Based Characterisation of Urban Environments on Satellite SAR Images. IEEE Transactions on Geoscience and Remote Sensing, 28, 540-552.

[13] Weydahl, D.J. (2002) Backscatter Changes of Urban Features Using Multiple Incidence Angle RADARSAT Images. Canadian Journal of Remote Sensing, 28, 782-793. http://dx.doi.org/10.5589/m02-072

[14] Chureesampant, K. and Susaki, J. (2012) Land Cover Classification Using Multi-Temporal Sar Data and Optical Data Fusion with Adaptive Training Sample Selection. IEEE Transactions on Geoscience and Remote Sensing, 6, 257-266. http://dx.doi.org/10.1109/igarss.2012.6352667

[15] Dobson, M., Ulaby, F.T. and Pierce, L. (1995) Land-Cover Classification and Estimation of Terrain Attributes Using Synthetic Aperture Radar. Remote Sensing of Environment, 51, 199-214. http://dx.doi.org/10.1016/0034-4257(94)00075-X

[16] Richards, J.A. (1990) Radar Backscatter Modelling of Forests: A Review of Current Trends. International Journal of Remote Sensing, 11, 1299-1312.

[17] Hagg, W. and Sties, M. (1994) Efficient Speckle Filtering of SAR Images. Proceedings of International Geoscience and Remote Sensing Symposium, 4, 2140-2142. http://dx.doi.org/10.1109/IGARSS.1994.399674

[18] Weng, Q. (2001) A Remote Sensing-GIS Evaluation of Urban Expansion and Its Impact on Surface Temperature in the Zhujiang Delta, Southern China. International Journal of Remote Sensing, 22, 1999-2014.

[19] Marceau, D.J., Howarth, P.J., Dubois, J.M. and Gratton, D.J. (1990) Evaluation of the Grey-Level Co-Occurrence Matrix Method for Land-Cover Classification Using SPOT Imagery. IEEE Transactions on Geoscience and Remote Sensing, 28, 513-519. http://dx.doi.org/10.1109/TGRS.1990.572937

[20] Lu, D., Batistella, M., Moran, E. and de Miranda, E.E. (2008) A Comparative Study of Landsat TM and SPOT HRG Images for Vegetation Classification in the Brazilian Amazon. Photogrammetric Engineering and Remote Sensing, 70, 311-321. http://dx.doi.org/10.14358/PERS.74.3.311

[21] Wen, C., Zhang, Y. and Deng, K. (2011) Urban Area Classification in High Resolution sar Based on Texture Features.

[22] Ban, Y. (2003) Synergy of Multitemporal ERS-1 SAR and Landsat TM Data for Classification of Agricultural Crops. Canadian Journal of Remote Sensing, 29, 518-526. http://dx.doi.org/10.5589/m03-014

[23] Pal, M. and Mather, P.M. (2003) Support Vector Classifiers for Land Cover Classification. Proceedings of Map India 2003 Conference, New Delhi, 28-31 January 2003.

[24] Amari, S. and Wu, S. (1999) Improving Support Vector Machine Classifiers by Modifying Kernel Functions. Neural Networks, 12, 783-789. http://dx.doi.org/10.1016/S0893-6080(99)00032-5

[25] Cristianini, N. and Shawe-Taylor, J. (2000) An Introduction to Support Vector Machines. Cambridge University Press, Cambridge, 204 p.

[26] Taati, A., Sarmadian, F., Mousavi, A., Pour, C.T.H. and Shahir, A.H.E. (2015) Land Use Classification Using Support Vector Machine and Maximum Likelihood Algorithms by Landsat 5 TM Images. Walailak Journal of Science and Technology, 12, 681-687.

[27] Foody, G.M. and Mathur, A. (2004) A Relative Evaluation of Multiclass Image Classification by Support Vector Machines. IEEE Transactions on Geoscience and Remote Sensing, 42, 1335-1343. http://dx.doi.org/10.1109/TGRS.2004.827257

[28] Candade, N. and Dixon, B. (2004) Multispectral Classification of Landsat Images: A Comparison of Support Vector Machine and Neural Network Classifiers. Proceedings of ASPRS Annual Meeting, Denver, 28 May 2004.

[29] Deilmai, B., Ahmad, B. and Zabihi, H. (2014) Comparison of Two Classification Methods (MLC and SVM) to Extract Land Use and Land Cover in Johor Malaysia. IOP Conference Series: Earth and Environmental Science, 20, Article ID: 012052.

[30] Manisha, B.P., Chitra, G. and Umrikar, N. (2012) Image Classification Tool for Land Use/Land Cover Analysis: A Comparative Study of Maximum Likelihood and Minimum Distance Method. International Journal of Geology, Earth and Environmental Sciences, 6, 189-196.

[31] Congalton, R.G. (1991) A Review of Assessing the Accuracy of Classifications of Remotely Sensed Data. Remote Sensing of Environment, 37, 35-46. http://dx.doi.org/10.1016/0034-4257(91)90048-B

[32] Furtado, L.F.A., Silva, T.S.F., Fernandes, P.J.F. and Novo, E.L.M. (2015) Land Cover Classification of Lago Grande de Curuai Floodplain (Amazon, Brazil) Using Multi-Sensor and Image Fusion Techniques. Acta Amazonica, 45, 195202. http://dx.doi.org/10.1590/1809-4392201401439

[33] Strozzi, T.M. and Kiffer, R.W. (2000) Remote Sensing and Image Interpretation. 4th Edition, John Wiley \& Sons, New 
York, 230 p.

[34] Grey, W. and Luckman, A. (2003) Mapping Urban Extent Using Satellite Radar Interferometry. Photogrammetric Engineering and Remote Sensing, No. 9, 957-962. http://dx.doi.org/10.14358/PERS.69.9.957

[35] UNEP (2008) Water Quality for Ecosystem and Human Health, United Nations Environment Programme Global Environment Monitoring System (GEMS)/Water Programme. 2nd Edition, 130 p.

[36] IPCC (2007) The Physical Science Basis (Summary for Policymakers); Contribution of Working Group I to the Fourth Assessment Report of the Intergovernmental Panel on Climate Change. IPCC, Geneva. http://www.ipcc.ch/SPM2feb07.pdf

[37] IPCC (2014) Climate Change 2014: Impacts, Adaptation, and Vulnerability. IPCC WGII AR5, Summary for Policymakers, WGII.

\section{Submit or recommend next manuscript to SCIRP and we will provide best service for you:}

Accepting pre-submission inquiries through Email, Facebook, LinkedIn, Twitter, etc.

A wide selection of journals (inclusive of 9 subjects, more than 200 journals)

Providing 24-hour high-quality service

User-friendly online submission system

Fair and swift peer-review system

Efficient typesetting and proofreading procedure

Display of the result of downloads and visits, as well as the number of cited articles

Maximum dissemination of your research work

Submit your manuscript at: http://papersubmission.scirp.org/ 